\title{
Enamel Shade: A Bright Future in Age Estimation
}

Rashmi Metgud ${ }^{\star}$, Payal and Smitha Naik

Department of Oral \& Maxillofacial Pathology, Pacific Dental College \&Hospital, Udaipur, Rajasthan, India

*Corresponding author: Dr. Rashmi Metgud, Department of Oral \& Maxillofacial Pathology, Pacific Dental College \& Hospital, Udaipur-313 024, Rajasthan, India, Tel: 09001829425; Fax: +91 294 2491508; E-mail: rashmi_metgud@rediffmail.com

Rec date: Oct 07, 2014 Acc date: June 27, 2015 Pub date: August 02, 2015

Copyright: (c) 2015 Metgud R, et al. This is an open-access article distributed under the terms of the Creative Commons Attribution License, which permits unrestricted use, distribution, and reproduction in any medium, provided the original author and source are credited.

\begin{abstract}
Teeth are useful indicators of age-at-death and non-destructive methods ensure preservation of dental evidentiary material which could be used for court presentation.
\end{abstract}

Aims and objectives: To evaluate correlation between the enamel color and chronological age. To estimate the age of an individual from enamel color.

Material and methods: A total of 150 subjects were studied which were divided into five groups based on age (age range 15-69 years) with 30 in each group. The enamel color was evaluated using a VITA classical shade guide.

Results: Present study reveals that younger age has reddish-yellow hue; middle age has yellowish hue, older age has yellow to greyish hue. The enamel color was found to be associated with chronological age.

Conclusion: Identification of individual age with no birth record can be done using enamel color. Further advance in enamel shade for age estimation with increased sample size would enhance the knowledge and improve the accuracy of methods used in the field of forensic odontology.

Keywords: Enamel shade; VITA classical shade guide; Identification; Enamel color; Age-at-death

\section{Introduction}

Forensic science is not local but global; which works in concert to address criminal justice issues, terrorism, missing persons, child abuse, and in mass disaster scenarios, refugees with disputed birth records. It is relevant not only in routine casework but also in mass fatalities resulting from natural phenomena (e.g. tsunami) and man-made catastrophes (e.g. terror attack) [1]. Dental profile can be developed from a person's mouth and teeth. It gives us an idea of racial characteristics like Asian and Native American populations as they have shovelled shaped incisors [2].

Cells in the nerves and roots of undamaged teeth possess the biological makeup (DNA) of an individual. Even teeth fragments allow investigators to determine an individual's DNA code via genetic testing. Sex of the person is proven by the presence or absence of a Y chromosome (male feature) in a tooth genetic profile [3]. Dental hard tissues are highly resistant to degradation and purification. This makes teeth as useful indicator for the calculation of age. Tooth color is considered better than most other regressive dental changes. Literature reveals that specific colour change of teeth is proportional with the increasing age and it is determined by internal and external tooth structure. A large volume of research has been published on age estimation especially in the field of forensic odontology [4].

Age estimation can be done by using various parameters such as Morphological parameter, Radiological parameter, Cementum thickness, Dentinal thickness, Volume of pulp tooth ratio, Incremental lines, Gustafson's method, but these are time consuming techniques and can be abandoned if a valid and time effective alternative is available. Very limited studies are reported using enamel shade for age estimation, hence keeping this in mind present study was conducted [1].

\section{Aims and Objectives}

To evaluate correlation between the enamel color and chronological age. To estimate the age of an individual from enamel color.

\section{Material and Methods}

A total of 150 subjects visiting the outpatient department of conservative and endodontic, and prosthodontics, pacific dental college and hospital, debari were selected. The subjects were divided into five groups based on age with 30 in each group. Group I: 15-25 years, Group II: 26-36 years, Group III: 37-47 years, Group IV: 48-58 years, Group V: 59-69 years. Inclusion criteria included healthy maxillary central, lateral incisor, canine, premolar and molar teeth i.e. free from cavities, breakage, and endodontically treated teeth or free from stain were selected. Oral prophylaxis was performed and shade was recorded under adequate natural light. Teeth were viewed at eye level. Shades were recorded quickly so to avoid eye fatigue (4-5 seconds). Exclusion criteria included endodontically treated teeth, Abnormal stains, Traumatic tooth, Teeth with cavities, Bright colors were excluded from field of view, Reported medical problem, History of tobacco chewing and smoking, Other occupational habits or birth trauma. 
The enamel color was evaluated using a VITA classical shade guide (Figure 1). The arrangement of shade in VITA classical family of shade is as follows:

A1-A4, B1-B4, C1-C4, D2-D4.The shade guide is arranged on the basis of hue difference from $\mathrm{A}$ to $\mathrm{D}$

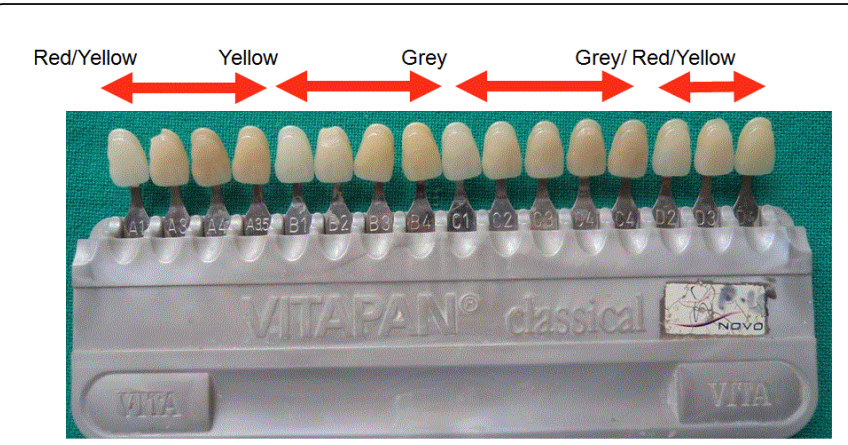

Figure 1: VITA classical shade guide.

After seating the patient on the dental chair (near adequate natural light) the shade guide was held parallel to the selected tooth at an arm's distance and the middle third of labial surface of tooth was matched with shade guide (Figures 2 and 3). Firstly value (lightness) of the color was assessed followed by hue and then chroma. Each tooth was observed for 4-5 seconds. All the observations were made in natural light. The surrounding was kept free from bright colors. Hue was selected closest to that of natural tooth. The entire study was carried out by 2 observers. The inter-examiner reliability was assessed using kappa coefficient (kappa=0.8). Data were exported to an excel spread sheet and statistical analysis were performed using the SPSS (version 17). Statistical analysis was carried out using linear regression equation and Chi-square test.

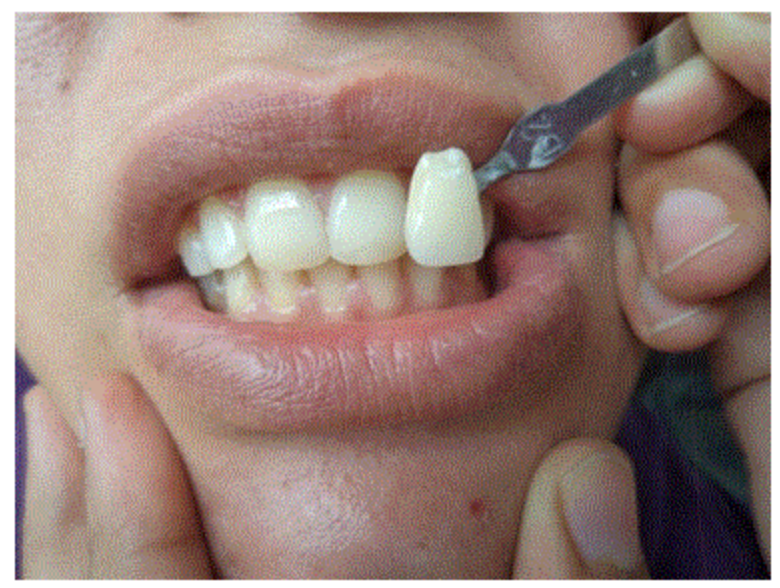

Figure 2: Evaluation of enamel color using VITA shade guide under natural light.

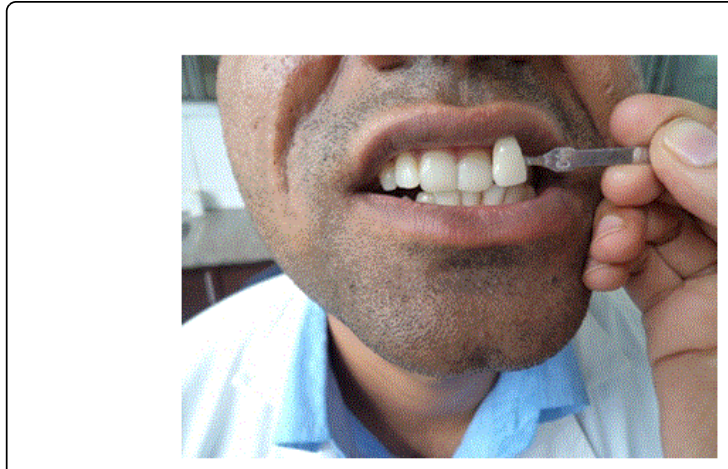

Figure 3: Evaluation of enamel color using VITA shade guide under natural light.

\section{Results}

In the present study a total 150 subjects were randomly selected. For the central and lateral incisors in the group 1 and 2 i.e. from 15-36 years the common shade was B1 (yellowish hue), for group 3 and 4 frequent shades was B2 (yellowish hue) and for group 5 i.e. in patient above 59 years C2 (grayish hue) was the common shade.

In general the most prevalent shade for central and lateral incisor was B2 (Table 1) and result obtained was statistically significant.

When the canine teeth were examined all the groups had A3 (Reddish hue?) shade in common and the results were statistically significant (Table 2).

For the premolars and molars B2 (yellowish hue) was the most common shade for groups I-IV, but the C2 (greyish hue) Shade was common in group V (Tables 3 and 4) and the results were statistically significant.

The commonest shade in the younger age groups was B1, B2 and $\mathrm{A} 3$, while $\mathrm{A} 3$ and $\mathrm{B} 2$ was common in middle age and $\mathrm{A} 3$ and $\mathrm{C} 2$ were common in old age (Table 5).

To establish the relationship between age and enamel color measured by VITA classical shade guide correlation coefficient (R) was calculated using age as dependent variable. The value of $\mathrm{R}$ was found to be 0.67 .

\begin{tabular}{|l|l|l|l|}
\hline Age Group & $\begin{array}{l}\text { Common } \\
\text { Shade }\end{array}$ & \multicolumn{2}{|l|}{$\%$ of Patients } \\
\hline I & B1 & $48.6 \%$ \\
\hline II & B1 & $48.6 \%$ \\
\hline III & B2 & $66.7 \%$ \\
\hline IV & B2 & $66.7 \%$ \\
\hline V & C2 & $63.3 \%$ & 0.000 (significant) \\
\hline Pearson chi square & $147.506^{\mathrm{a}}$ & 36 & \multicolumn{2}{|l|}{} \\
\hline
\end{tabular}

Table 1: Percentage of closest shades matched to the examined central and lateral incisor teeth in different age group indicated by VITA classical guide. 
Page 3 of 4

\begin{tabular}{|l|l|l|l|}
\hline Age Group & Common Shade & \multicolumn{2}{l|}{$\%$ of Patients } \\
\hline I & A3 & $62.2 \%$ \\
\hline II & A3 & $52.8 \%$ \\
\hline III & A3 & $50 \%$ \\
\hline IV & A3 & $63.3 \%$ \\
\hline V & A3 & $60 \%$ & \\
\hline Pearson chi square & 51.731 & 24 & 0.001 (significant) \\
\hline
\end{tabular}

Table 2: Percentage of closest shades matched to the examined canine teeth in different age group indicated by VITA classical guide.

\begin{tabular}{|l|l|l|l|}
\hline Age Group & Common Shade & $\%$ of Patients \\
\hline I & B2 & $56.7 \%$ \\
\hline II & B2 & $55.5 \%$ \\
\hline III & B2 & $66 \%$ \\
\hline IV & B2 & $63.3 \%$ \\
\hline V & C2 & $63.3 \%$ \\
\hline Pearson chi square & 147.506 & 36 & 0.000 (significant) \\
\hline
\end{tabular}

Table 3: Percentage of closest shades matched to the examined premolar teeth in different age group indicated by VITA classical guide.

\begin{tabular}{|l|l|l|l|}
\hline Age Group & Common Shade & \multicolumn{2}{|l|}{$\%$ of Patients } \\
\hline I & B2 & $62.2 \%$ \\
\hline II & B2 & $61.1 \%$ \\
\hline III & B2 & $63.3 \%$ \\
\hline IV & B2 & $63.3 \%$ \\
\hline V & C2 & $63.3 \%$ & \\
\hline Pearson chi square & 116.953 & 28 & 0.000 (significant) \\
\hline
\end{tabular}

Table 4: Percentage of closest shades matched to the examined molar teeth in different age group indicated by VITA classical guide.

\begin{tabular}{|l|l|l|}
\hline & Age & Enamel shade \\
\hline Group 1 & $15-25$ year & B1, A3, B2 \\
\hline Group 2 & $26-36$ year & B1, A3, B2 \\
\hline Group 3 & $37-47$ year & A3, B2 \\
\hline Group 4 & $48-58$ year & A3, B2 \\
\hline Group 5 & $59-69$ year & C2, A3 \\
\hline
\end{tabular}

Table 5: Percentage of the closest shade match to the examined subject's teeth in different age groups as indicated by the VITA classical shade guide.

\section{Discussion}

Color alteration of teeth, due to wear and degeneration of hard tissue, are a unique indicator of aging over time. The main goal of forensic dentistry is to provide information about the possible cause, time and place of death. Forensic dentist's opinion is very important for judicial audience in any crime or mass disaster scenarios. The viability of teeth and jaw remaining intact in extreme temperature and explosions is the central reason for forensic dentist's role in medicolegal death investigation [1].

Various methods used for age estimation have some drawbacks such as gustafson's method has drawback related to age structure and variability of samples as well as statistical analysis. Radiograph based method use only one or two dimensional measurement and don't comprehensively investigate three dimensional decrease in pulp cavity caused by age related formation of secondary dentin [5]. Munsell color system includes hue, value, and chroma. Visual matching has been preferred over spectrophotometer and digital technique due to easy availability and cost effectiveness [6]. Hence the present study was planned.

Color of teeth in the majority of young population is brighter and less yellow, whereas in elder population teeth become yellowish and grayish over time. Certain factors affecting tooth color are physiological changes, life style of an individual, consumption of different food and beverages, geographical location, ageing1.Geneticcomplexion or the colour of eyes, teeth may appear yellower, browner or greyer due to inherited genes, physical properties of an object, assessment of an observer, nature of incident light, thickness of enamel, volume of pulp chamber, thickness of dentin [3,7].

As teeth are less affected by fluctuating environmental conditions in the first few weeks of death than soft tissue and inner organs, a known pattern of post-mortem changes in teeth color over time could yield more reliable information regarding time since death. However, color changes in one individual over year follow a predictable pattern unless some extreme life events or bad habits are present .Therefore, it might be possible to recalculate the color of particular person using regression analysis. For this reason, if further research show usefulness of teeth color for age estimation and identification, building a teeth color-database could be of huge interest [1]. The results obtained in the present study reveal that younger age has reddish-yellow hue; middle age has yellowish hue, older age has yellow to grayish hue (Figures 2 and 3). This finding is consistent with the findings of Vivev $\mathrm{k}$ singh et al. who conducted a study on role of enamel color in age estimation using a dental shade guide: A study in the tricity region of Chandigarh 8.Yellowish color may be because of the color of dentin revealed through thin enamel. During aging, composition of the surface layer changes as ionic exchange with the oral environment occurs [8]. Enamel color was found to be associated with the chronological age $(\mathrm{R}=0.67)$.Mean age difference of calculated age and actual age was $+/-6$ year. Findings by observer and co-observer were almost similar; pointing to the fact that the subjective type of measurement has not influenced the result.

This is a preliminary study in which color of enamel served as a significant method for age estimation. Further studies are required to evaluate changes in the thickness of dentin, enamel, size of pulp chamber with advancing age, in order to improve the age estimation using tooth color. 


\section{Conclusion}

Identification of individual age with no birth record can be done using enamel color. Further advance in enamel shade for age estimation with increased sample size would enhance the knowledge and improve the accuracy of methods used in the field of forensic odontology.

\section{References}

1. Bajasman, SadetaSecic, AnjaPetaros (2011) Spectrophotometric evaluation of color alteration of teeth exposed to different condition in time. International Journal of oral science and dental medicine.

2. Babshet M, Acharya AB, Naikmasur VG (2010) Age estimation in Indians from pulp/tooth area ratio of mandibular canines. Forensic Sci Int 197: 125.
3. Kenney JP (2006) Domestic violence: a complex health care issue for dentistry today. Forensic Sci Int 159 Suppl 1: S121-125.

4. Lagouvardos PE, Diamanti H, Polyzois G (2004) Effect of individual shades on reliability and validity of observers in colour matching. Eur J Prosthodont Restor Dent 12: 51-56.

5. Devos N, Willems G, Wood R (2009) Objective human tooth colour measurements as a means of determining chronologic age in vivo and ex vivo. J Forensic Odontostomatol 27: 2-8.

6. Andrew Joiner, Ian Hopkinson, Yan Deng, Stephen Westland (2008) A review of tooth color and whitness. Journal of dentistry 36s: s2-s7.

7. Martin-de las Heras S, Valenzuela A, Bellini R, Salas C, Rubiño M, et al. (2003) Objective measurement of dental color for age estimation by spectroradiometry. Forensic Sci Int 132: 57-62.

8. Singh V, Sethi P, Saluja R, Singh D (2010) Role of enamel color in age estimation using a dental shade guide:A study in the tricity region of Chandigarh, Mohali, Panchkula. J Punjab Acad Forensic Med Toxicol 10. 